Military Technical College Kobry El-Kobbah, Cairo, Egypt

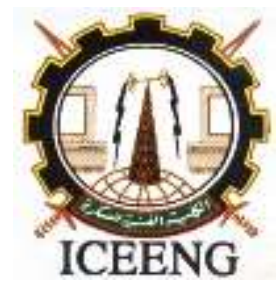

$11^{\text {th }}$ International Conference on Electrical Engineering ICEENG 2018

\title{
OPTICAL ACCESS NETWORKS: A COMPARISON STUDY
}

M. D. Hussien *, A. A. Mohamed*, M. I. Hosni*, A. M. Mokhtar*, M. M.Youssef* and K. M. Hassan**

\section{ABSTRACT}

A comparison study of passive Optical Networks (PONs) and Active Optical Networks (AONs) had been presented. Powerful software design tool "OptiSystem" was used to perform this study. This comparison was based in terms of power consumption, communication distance, Q-factor, and bit error rate (BER) for each network system.

\section{KEY WORDS}

FTTX, PON, AON, PtP, Optical access networks

* Egyptian Armed Forces.

** Electrical Engineering Dept., FUE, Cairo, Egypt. 


\section{INTRODUCTION}

There are fast steps to improve the broadband services and increase the bandwidth of the new services, such as HDTV, broadcast TV / radio, home online games, remote medical services and next-generation 3D TV. That will be done by using network architecture which depends on optical fiber cables instead of copper cables [1-5]. Because of the fact that optical fiber has higher capacity than both coaxial cables and wireless links with lower latency and higher availability to reach longer area, optical fiber was studied to be used in broadband access networks as currently it can support data rate of more than $10 \mathrm{~Gb} / \mathrm{s}$ in both upstream and downstream, also it can support the future demands by reaching $10-40 \mathrm{~Gb} / \mathrm{s}$ with long distance and serving great number of users. That's why Fiber To the $X$ (FTTX) is used which defined telecommunication systems that based on optical fiber $[2,3,6,7]$. There are two networks that define the Optical access networks which gather data from the end users and forward it towards the central office and in the opposite direction data will be distributed from the central office to the end users. These networks are called Active Optical Network (AON) or Active Ethernet, and Passive Optical Network (PON) as shown in Fig.1 [2]. Active Ethernet or Active Optical Network (AON) is standardized according to IEEE 802.3 standard [8], it is used for broadband services (4/5 G for mobile network - Ultra High definition TV - Video conferencing - .. ) [3, 9]. It depends on devices which are electrically powered such as routers and switches to distribute the signal $[2,10]$. There is a dedicated Ethernet connection to each user that provide dedicated bandwidth of about $1 \mathrm{~Gb} / \mathrm{s}$ for each user which is acceptable for the current triple play services (voice - video - data) [2, 9, 11]. Nowadays it can support applications with bandwidth of $10 / 40 / 100 \mathrm{~Gb} / \mathrm{s}$ to each user and in future it can support $400 \mathrm{~Gb} / \mathrm{s}$ [8] .There are two types of the AON which are based on active Ethernet switch, Point to point (PtP) and Active Star (AS). In PtP, there is a dedicated fiber link between Optical Network Terminal (ONT), Residential Gateway (RG) and the Ethernet switch of Optical Line Terminal (OLT) inside the Central Office (CO) as shown in Fig.2 (a) $[9,11]$. In AS there is an Active Remote Node (RN) which is an Ethernet switch, and it is located in a cabinet or a building for connecting multiple (RGs) as shown in Fig.2 (b) [9, 11]. PONs are the principal networks for the broadband access Networks which are also fiber access network, they are called Passive networks as they don't use any active electrically powered equipment like that used in the AON (Ethernet switch), instead they only use passive components such as splitters or filters $[3,12]$. Their architectures are based on main components which are an OLT, Optical Distribution Network (ODN), and Optical Network Units (ONU) as shown in Fig.3 [13]. PONs are used to provide customers with multimedia services (internet - TV - VOIP phone - internet services) with high data rate and through a network which is low cost and easy to implement [13]. The important parameters that govern the performance of the optical fiber networks are the signal to noise ratio (SNR), Q-factor, and the BER. SNR is described by the following formula [1]:

$$
\operatorname{SNR}(d B)=10 \log \left(P_{\text {out }} / P_{N}\right)
$$

SNR is the signal to noise ratio which is the ratio between the average signal power ( $P_{\text {out }}$ ) to the average noise power $\left(P_{N}\right)$. The $Q$ factor measures the quality of the signal in terms of signal to noise ratio (SNR) and is given by [6]: 


$$
Q_{d B}=S N R+10 \log \left(B_{c} / B_{0}\right)
$$

Where $B_{c}$ is the electrical bandwidth of the receiver filter and $B_{0}$ is the optical bandwidth of the photodetector. The Bit error rate (BER) has a relation with $Q$ factor in terms of error function (erfc), and is defined in the following formula [6, 14]:

$$
\begin{aligned}
\mathrm{BER} & =\frac{1}{2} \operatorname{erfc}(\mathrm{Q} / \sqrt{2}) \\
\text { erfc } & =\frac{2}{\pi} \int_{0}^{x} e^{-t^{2}} d t
\end{aligned}
$$

PONs are defined and standardized by the International Telecommunications Union (ITU), the Institute of Electrical and Electronic Engineers (IEEE), and Full Service Access Network (FSAN) group to form the main architectures and the developed versions of PONs (APON - BPON - GPON - EPON) on which the commercial PONs nowadays are GPON and EPON [13]. PON technology is classified into generations, the first generation which are already deployed (APON - BPON - GPON - EPON), the first step of the next generation NG-PON1 which includes (XG-PON and XG-EPON), and the second step of the next generation NG-PON2 as shown in Fig.4 [13]. Table 1

\begin{tabular}{|c|c|c|c|c|c|}
\hline $\begin{array}{c}\text { Points Of } \\
\text { Comparison }\end{array}$ & BPON & GPON & XG-PON & EPON & XG-EPON \\
\hline Standard & G.983 & G.984 & G.987 & $\begin{array}{c}\text { IEEE } \\
802.3 a h\end{array}$ & $\begin{array}{c}\text { IEEE } \\
802.3 a v\end{array}$ \\
\hline DS bit rate & $\begin{array}{l}1.24 \\
\mathrm{~Gb} / \mathrm{s}\end{array}$ & $\begin{array}{c}1.244 \mathrm{~Gb} / \mathrm{s} \\
2.5 \mathrm{~Gb} / \mathrm{s}\end{array}$ & $10 \mathrm{~Gb} / \mathrm{s}$ & $1.25 \mathrm{~Gb} / \mathrm{s}$ & $\begin{array}{c}1 \mathrm{~Gb} / \mathrm{s} \text { or } \\
10 \mathrm{~Gb} / \mathrm{s}\end{array}$ \\
\hline US bit rate & $\begin{array}{c}622 \\
\mathrm{Mb} / \mathrm{s}\end{array}$ & $\begin{array}{c}155 \mathrm{Mb} / \mathrm{s} \\
622 \mathrm{Mb} / \mathrm{s} \\
1.244 \mathrm{~Gb} / \mathrm{s} \\
2.5 \mathrm{~Gb} / \mathrm{s}\end{array}$ & $\begin{array}{c}1 \mathrm{~Gb} / \mathrm{s}, 10 \\
\mathrm{~Gb} / \mathrm{s}\end{array}$ & $1.25 \mathrm{~Gb} / \mathrm{s}$ & $10 \mathrm{~Gb} / \mathrm{s}$ \\
\hline $\begin{array}{c}\text { DS } \\
\text { wavelength }\end{array}$ & $\begin{array}{c}1490 \\
\mathrm{~nm}\end{array}$ & $\begin{array}{c}\text { 1480-1500nm } \\
\text { 1550-1560nm } \\
\text { (video) }\end{array}$ & $\begin{array}{c}1575-1580 \\
\mathrm{~nm}\end{array}$ & $\begin{array}{c}1480-1500 \\
\mathrm{~nm}\end{array}$ & $\begin{array}{c}1480-1500 \\
\mathrm{~nm}\end{array}$ \\
\hline $\begin{array}{c}\text { US } \\
\text { wavelength }\end{array}$ & $\begin{array}{c}1310 \\
\mathrm{~nm}\end{array}$ & $1300-1320 \mathrm{~nm}$ & $\begin{array}{c}1260-1280 \\
n m\end{array}$ & $\begin{array}{c}1260-1360 \\
\mathrm{~nm}\end{array}$ & $\begin{array}{c}1260-1280 \\
\mathrm{~nm}\end{array}$ \\
\hline Distance & $20 \mathrm{Km}$ & $60 \mathrm{~km}$ & $20 \mathrm{Km}$ & $20 \mathrm{Km}$ & $20 \mathrm{~km}$ \\
\hline Splitting ratio & $1: 32$ & $1: 64$ & $1: 256$ & $1: 16$ & $1: 32$ \\
\hline
\end{tabular}
shows the main characteristics of different types of PONs [3, 5-7, 10, 13]:

Table.1 The main characteristics of different types of PONs

The purpose of this paper is to provide a comprehensive comparison between AONs, and the PONs with respect to performance, ease of implementation, and cost effectiveness, using the powerful simulation tool OptiSystem. Using the proposed simulation results, we can identify in which cases PONs are preferable and in which cases AONs are preferable. 


\section{SIMULATION RESULTS AND ANALYSIS}

Optisystem7 was used to perform a comparison between a type of AON (PtP) with dedicated BW for each user, and a type of PONs (GPON) with shared BW in terms of distance, $B E R$ and $Q$ factor. Our requirements were to choose two networks with the same parameters as possible according to standards for appropriate comparison. Based on the Ethernet standard IEEE 802.3, a system of AON PtP FTTH type is simulated by considering using bidirectional small form-factor pluggable transceiver (SFP), while the GPON is simulated based on ITU-T G.984, with the following simulation parameters shown in Table.2:

Table.2 Simulation parameters for the investigated networks

\begin{tabular}{|l|c|c|}
\hline \multicolumn{1}{c}{ Components } & GPON & \multicolumn{1}{c|}{ AON (PtP) } \\
\hline Bit rate & $1.244 \mathrm{~Gb} / \mathrm{s}$ & $1.244 \mathrm{~Gb} / \mathrm{s}$ \\
\hline Bit sequence Generator & $\mathrm{NRZ}$ & $\mathrm{NRZ}$ \\
\hline Downstream Wave length & $1490 \mathrm{~nm}$ & $1490 \mathrm{~nm}$ \\
\hline Upstream wavelength & $1310 \mathrm{~nm}$ & $1310 \mathrm{~nm}$ \\
\hline Downstream power & $(-3,-1,1,3) \mathrm{dBm}$ & $-3 \mathrm{dBm}$ \\
\hline Fiber Distance & $(10,15,20,25,30,35,40,50) \mathrm{Km}$ \\
\hline Number of ONUs & 8 & 8 \\
\hline Power Splitter & $1: 8$ & - \\
\hline Photodetector (Type) & PIN & PIN \\
\hline
\end{tabular}

There are common main components in the two networks, such as Continuous Wave Laser which acts as an Optical Source, Pseudo Random Bit Sequence Generator (PRBS) that determines the data rate, NRZ modulator which is the modulation method and MachZehnder Modulator which is used to control the amplitude of the optical wave. All of these components are under the transmitter section as shown in Fig.5. In the receiver section as shown in Fig.6, Bessel Filter is a shaping feature on which it is used to preserve the shape of the pass band signal, PIN Photodiode is used to convert optical signal into electrical signal, Low pass filter is used to cut the high Bessel frequencies, Optical Regenerator $3 R$ is connected with BER analyzer to show the eye diagram and make performance analysis of the received signal in terms of quality and bit error rate. For the used optical fiber, we used OptiFiber program and connected it with the Optisystem to determine the attenuation $(0.362 \mathrm{~dB} / \mathrm{Km}$ for 1310 $\mathrm{nm}-0.216 \mathrm{~dB} / \mathrm{Km}$ for $1490 \mathrm{~nm}$ ), dispersion $0.401 \mathrm{ps} / \mathrm{Km} . \mathrm{nm}$ for $1310 \mathrm{~nm}-13.321$ ps/ Km.nm for $1490 \mathrm{~nm}$ ), and nonlinear refractive index $\left(\mathrm{n}_{2}\right)$ according to Kerr effect $\left(2.607 \mathrm{e}^{-20} \mathrm{~m}^{2} / \mathrm{W}\right.$ for $1310 \mathrm{~nm}-2.51 \mathrm{e}^{-20} \mathrm{~m}^{2} / \mathrm{W}$ for $\left.1490 \mathrm{~nm}\right)$ in the fiber as a function of wavelength. In Fig.7, the structure of GPON has only one transmitter that launches signal towards a fiber which is connected to a passive splitter with ratio $1: 8$ used to distribute and divide the signal towards 8 ONUs. Our requirement in this simulation is to reach distance of $40 \mathrm{~km}$ with minimum power from $(-3 \mathrm{dBm}$ to $3 \mathrm{dBm})$, consequently, for GPON by using variable transmitted power for downstream $(-3,-1$, 1 , 3) $\mathrm{dBm}$ to transmit signal through different fiber lengths $(10,20,30,40) \mathrm{Km}$, the relation between BER and fiber length is plotted in Fig.8. Knowing that the acceptable BER is $10^{-12}$; it is concluded that the maximum distance that can be achieved by -3 $\mathrm{dBm}$ is $13 \mathrm{Km}$, by $-1 \mathrm{dBm}$ is $19 \mathrm{Km}$, by $1 \mathrm{dBm}$ is $28 \mathrm{Km}$, and by $3 \mathrm{dBm}$ is $40 \mathrm{Km}$. Simulation results show that for GPON at the maximum achieved distance of $40 \mathrm{Km}$ by using transmitted power of $3 \mathrm{dBm}$, the $Q$ factor was 6.994 and the BER was $1.3 \times$ 
$10^{-12}$ as shown in the eye diagram of Fig.9. Fig.10 shows the structure of the investigated AON PtP that consists of a central office / OLT which contained a transmitter followed by fork with 8 branches to simulate that the central office contains 8 transmitters, so that each ONU is connected to a fiber with dedicated transmitter. The simulation results show that the AON structure can easily achieve distance of $40 \mathrm{Km}$ for all 8 ONUs using 8 transmitters with only $-3 \mathrm{dBm}$ transmitted power and provide a $Q$ factor of 10.23 and BER of $7.07 \times 10^{-25}$ for each user as shown in Fig.11. It can be concluded that $A O N$ has better $Q$ factor and lower BER than GPON at $40 \mathrm{Km}$, as a result of the existence of dedicated bandwidth and dedicated fiber for each user, However it suffers from high power consumption as the power consumption used for 8 transmitters in AON to transmit total power of $6.03 \mathrm{dBm}$ $(-3 \mathrm{dBm} \times 8)$ of course is more than the power consumption of GPON which uses only one transmitter with maximum power of $3 \mathrm{dBm}$ to reach distance of $40 \mathrm{Km}$. Simulation results also show that by increasing the fiber link length to $50 \mathrm{Km}$ there is no acceptable results for GPON as the $Q$ factor and BER are 4.16, and1.52 $\times 10^{-5}$, respectively as shown in Fig.12. However $A O N$ reached $50 \mathrm{Km}$ with $Q$ factor of 7.704 and BER of $6.57 \times 10^{-15}$ as shown in Fig.13. Table 3 and Table 4 summarize the conclusion from the proposed comparison between the investigated networks obtained from the simulation results.

Table 3 Summary results of the proposed simulation networks.

\begin{tabular}{|c|c|c|c|c|c||c|c|}
\hline \multicolumn{9}{|c|}{ PON } & \multicolumn{3}{c|}{ AON } \\
\hline Power (dBm) & -3 & -1 & 1 & 3 & 3 & -3 \\
\hline $\begin{array}{c}\text { Maximum } \\
\text { distance (Km) }\end{array}$ & 13 & 19 & 28 & 40 & 50 & 40 & 50 \\
\hline BER & \multicolumn{3}{|c|}{$10^{-12}$} & $1.52 \times 10^{-5}$ & $7.07 \times 10^{-25}$ & $6.57 \times 10^{-15}$ \\
\hline
\end{tabular}

Table 4 Conclusion of the comparison between the investigated networks

\begin{tabular}{|c|c|c|}
\hline Points Of Comparison & PON & Active Ethernet / AON \\
\hline Equipment & $\begin{array}{c}\text { Not electrically powered } \\
\text { (switch - Filter) }\end{array}$ & $\begin{array}{l}\text { Electrically powered } \\
\text { (Switch - Router) }\end{array}$ \\
\hline Topology & Point to multipoint & Point to point \\
\hline Power consumption & Low & High \\
\hline Bandwidth & Shared & Dedicated for each user \\
\hline Capacity for each subscriber & Low & High \\
\hline Secure & Less & More \\
\hline Upgrade & Difficult & Simple \\
\hline Distance to reach & Short & Far \\
\hline Cost & Low & High \\
\hline Simplicity & Simple & Complex \\
\hline
\end{tabular}

\section{Description of any Case Study}


According to our results and the previous comparison between AON and PON in terms of advantages and limitations of each one of them as shown in Table 4, Choosing between these two types of optical networks will depend on the customer's need, requirements, and resources. Such as what kind of services are going to be delivered over the optical network, the overall network topology, the required distances, the level of security, the available transmitted power, the required number of subscribers / end users, and finally the cost.

\section{CONCLUSION}

The simulation results of the proposed study shows that the advantages of AONs over PONs are higher capacity as each user has a dedicated BW (not shared), longer communication distance, and more secure than PON. Because of the absence of active components, PON has advantages over AON such as reduced cost, simpler maintenance, low power consumption, and reduced size because of using only one shared fiber. The proposed simulation results showed that for reaching distance of $40 \mathrm{~km}$ using specific transmitted power from $-3 \mathrm{dBm}$ to $3 \mathrm{dBm}$, it is better to use PON than $A O N$ if our first priority is for the power consumption and the cost. However if we want to transmit data for longer distance $(50 \mathrm{Km})$, AON will be used as the BER at the end users for PON is $1.52 \times 10^{-5}$ which is not acceptable but for AON the BER is $6.57 \times 10^{-15}$.

\section{FIGURES}

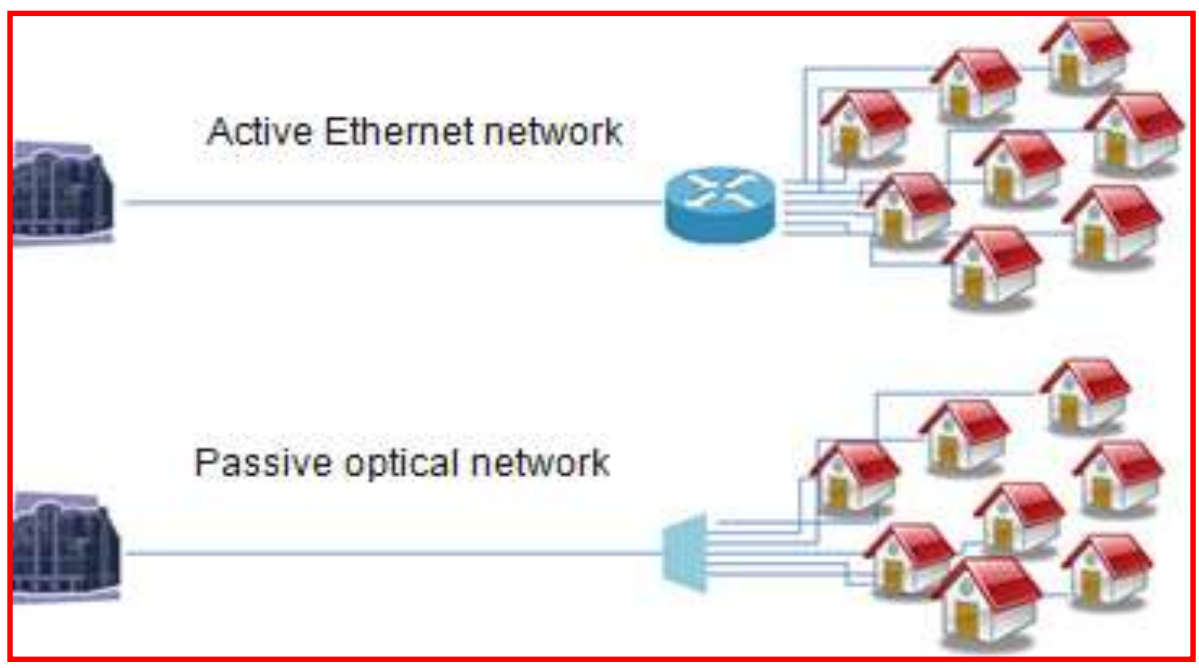

Fig.1. Active Ethernet and Passive Optical Network [2]. 


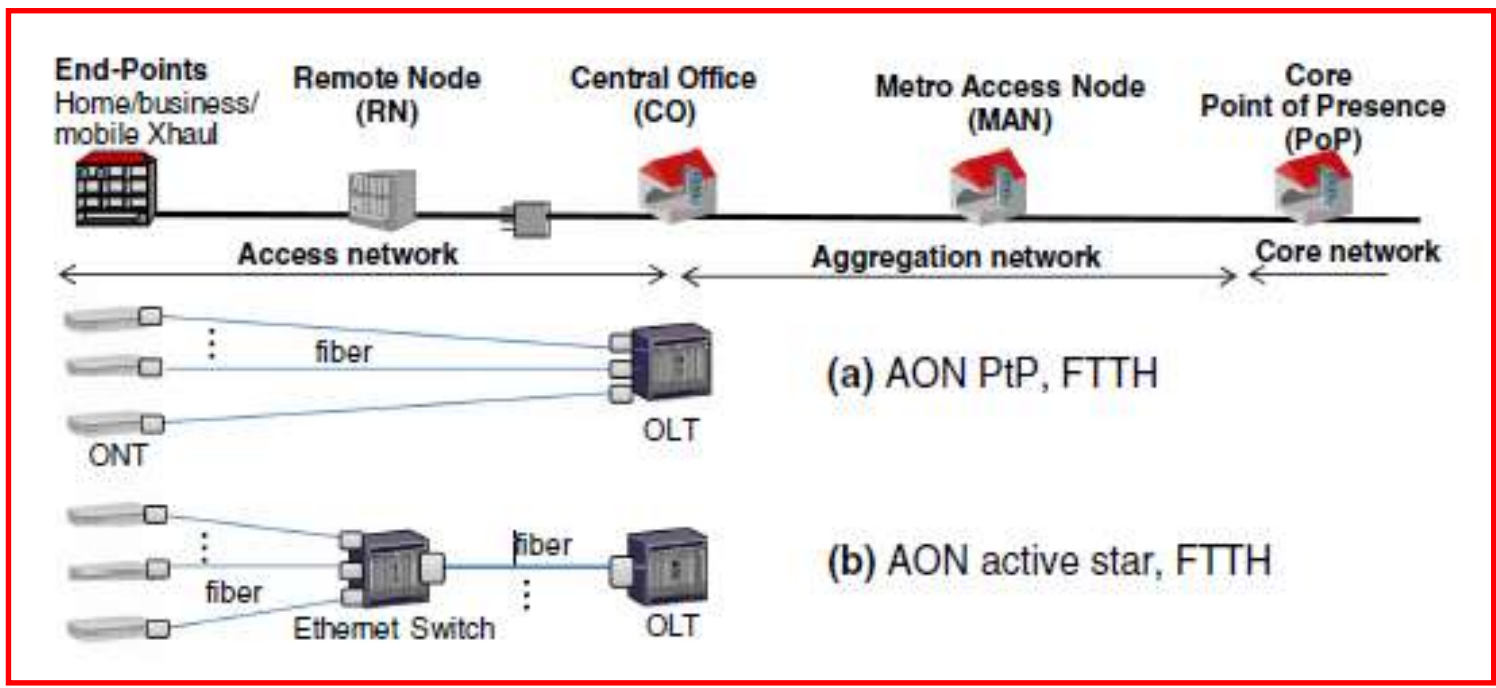

Fig. 2. a) AON P2P; b) AON active star [11].

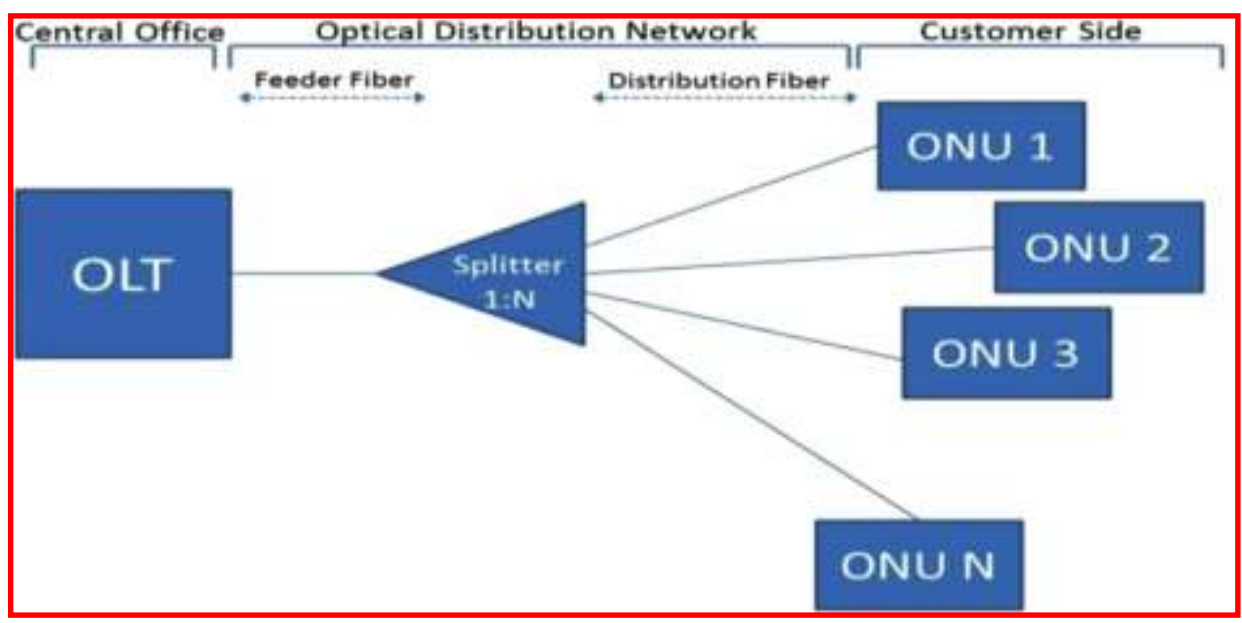

Fig.3.PON's Architecture [13].

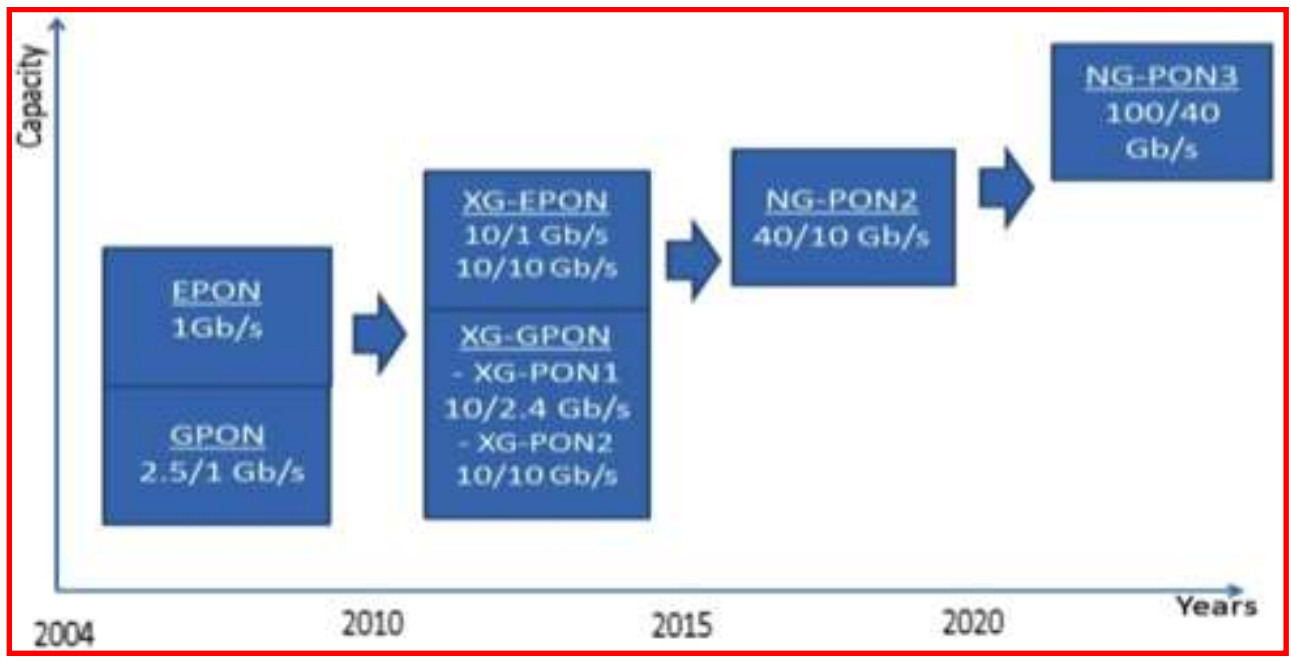

Fig.4.Generations of PONs [13]. 


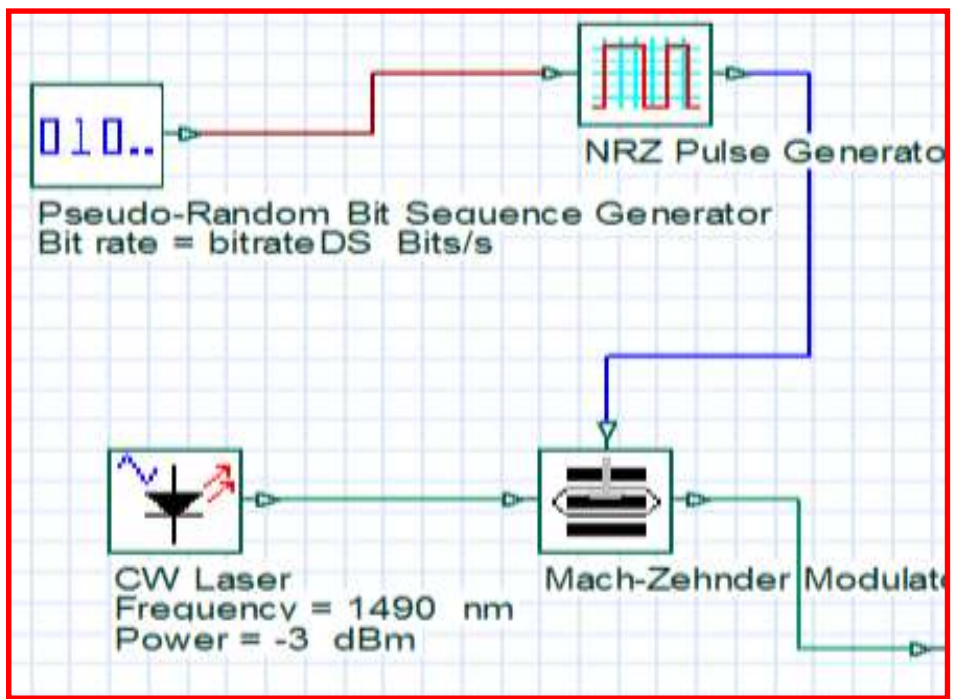

Fig.5. Structure of the transmitter.

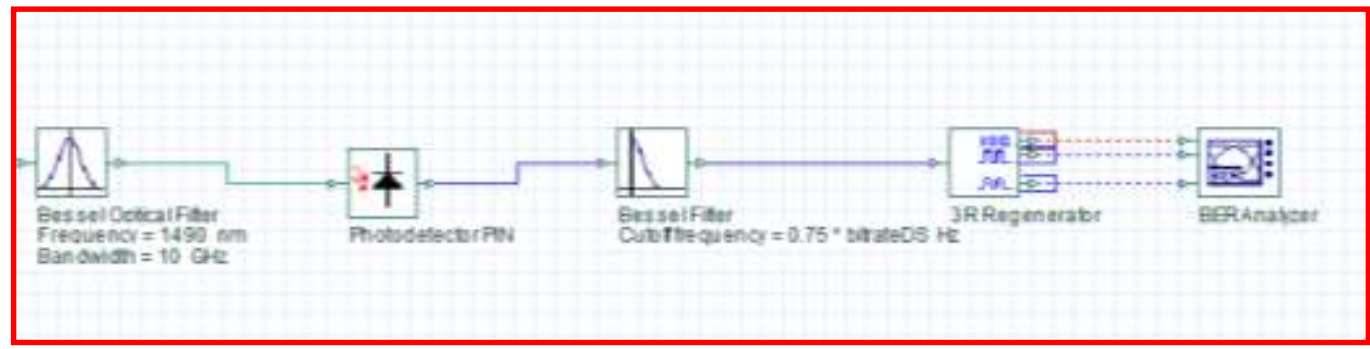

Fig.6. Structure of the receiver.

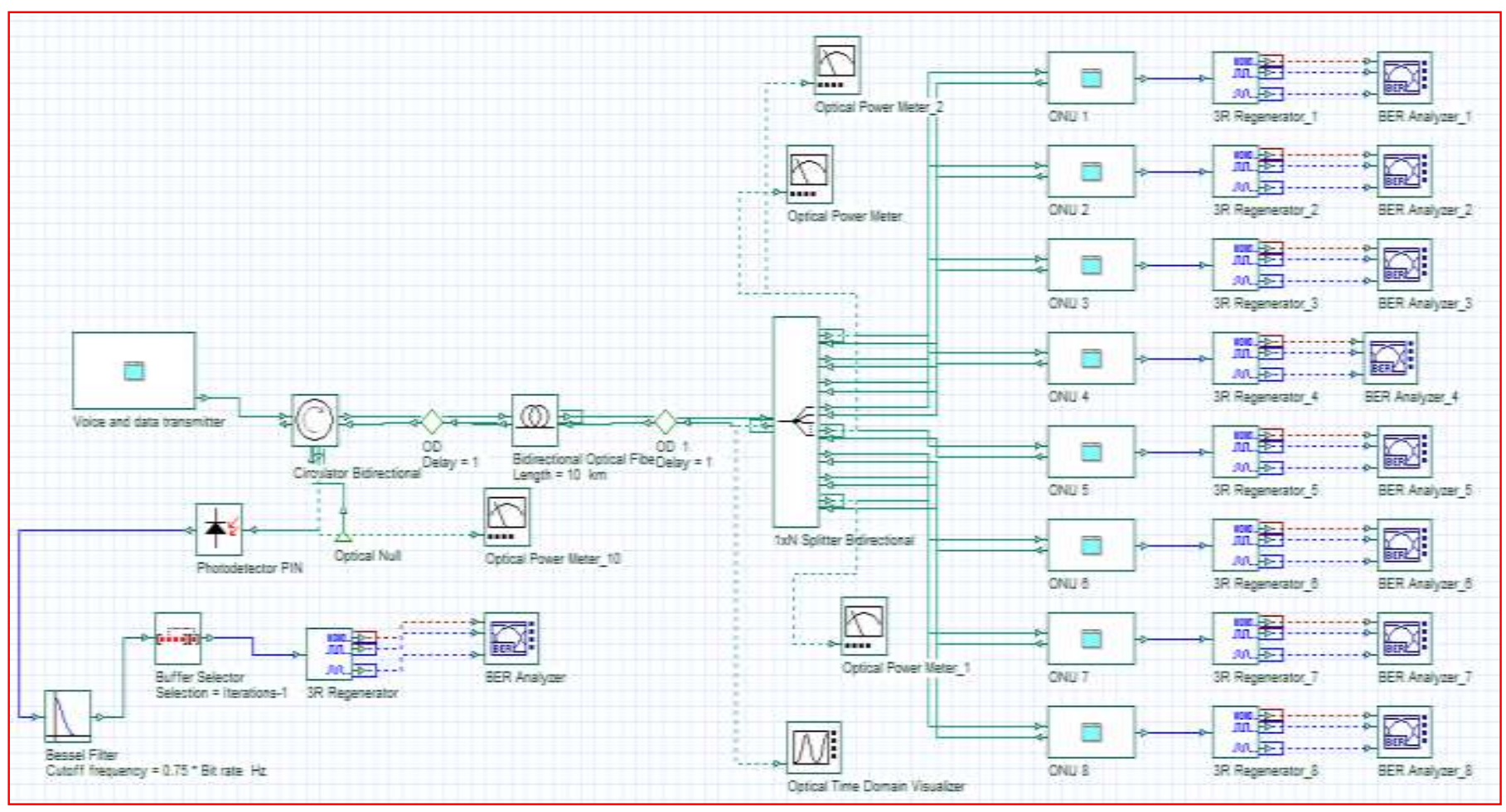

Fig.7. Structure of the investigated GPON 


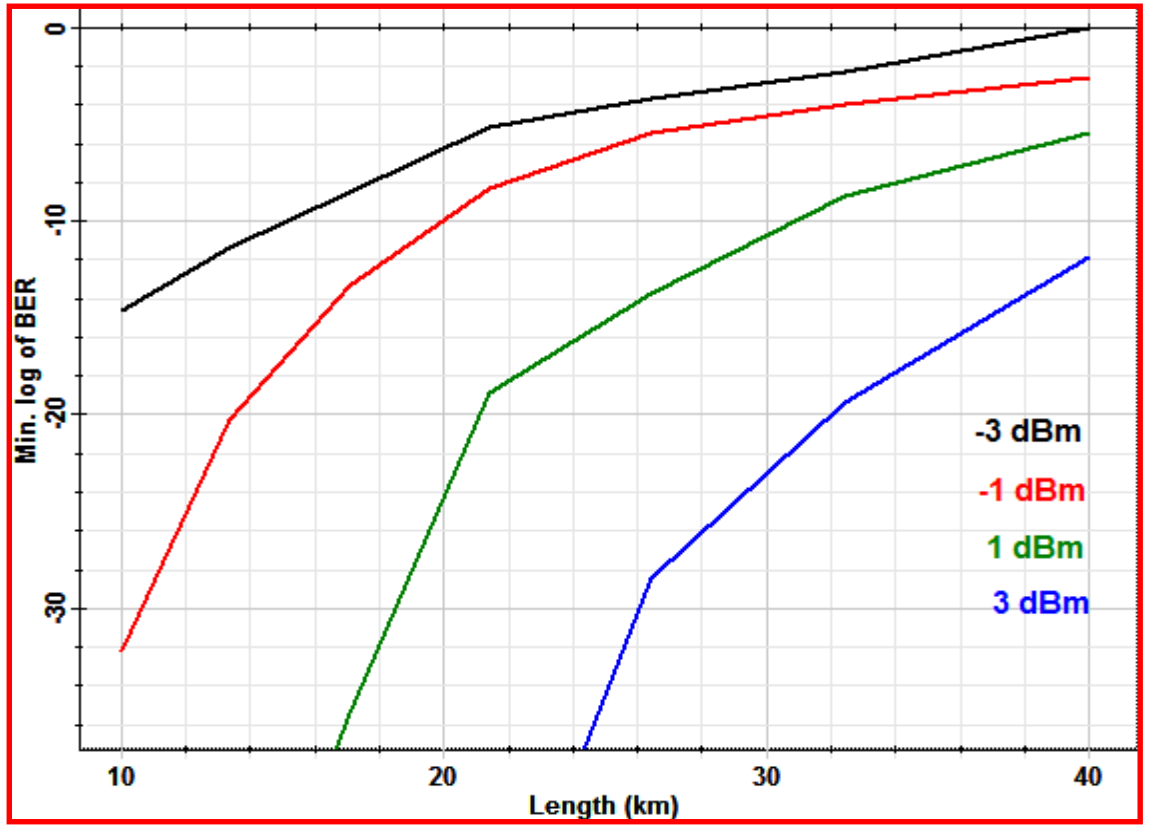

Fig.8. BER versus fiber length for PON case with using different power sources.

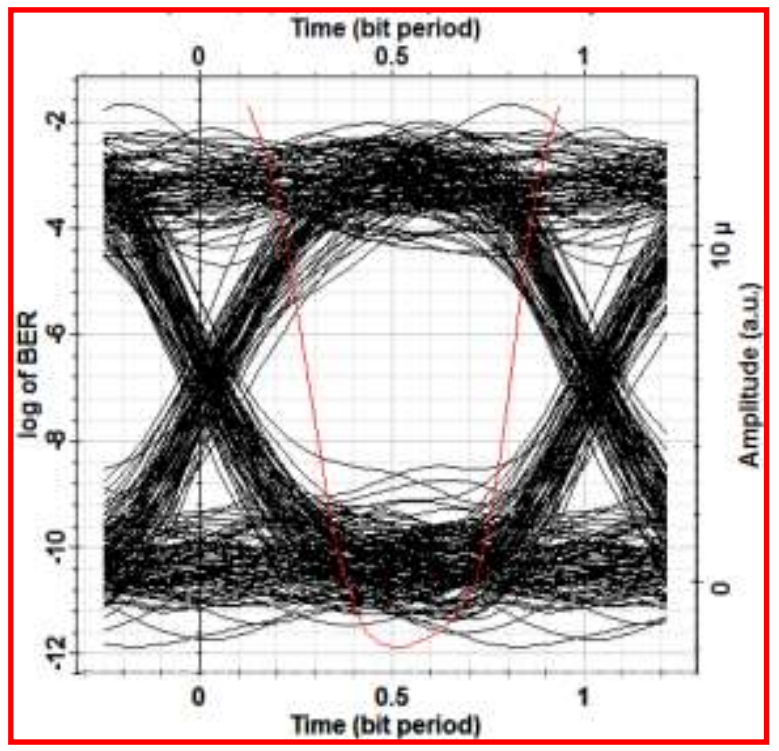

Fig.9. Eye diagram for GPON at distance $40 \mathrm{~km}$ using $3 \mathrm{dBm}$ transmitted power 


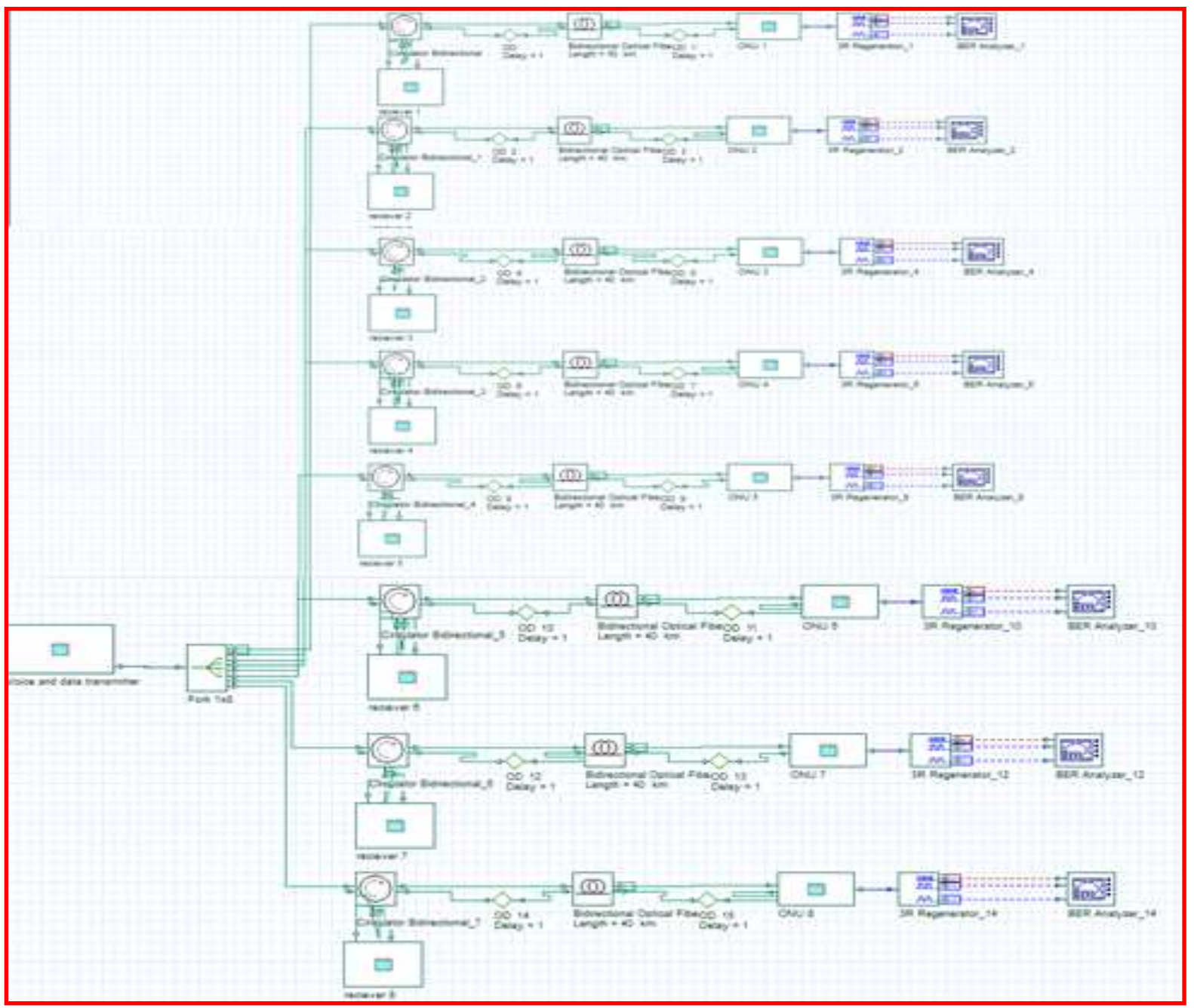

Fig.10. Structure of AON PtP.

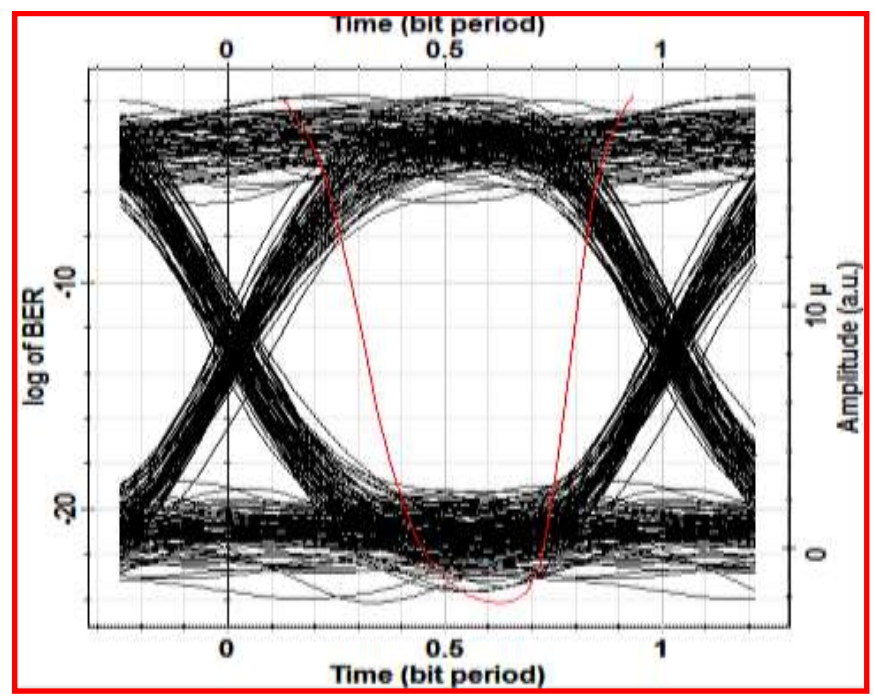

Fig.11. Eye diagram for AON PtP at distance $40 \mathrm{~km}$ using transmitted power of $-3 \mathrm{dBm}$ 


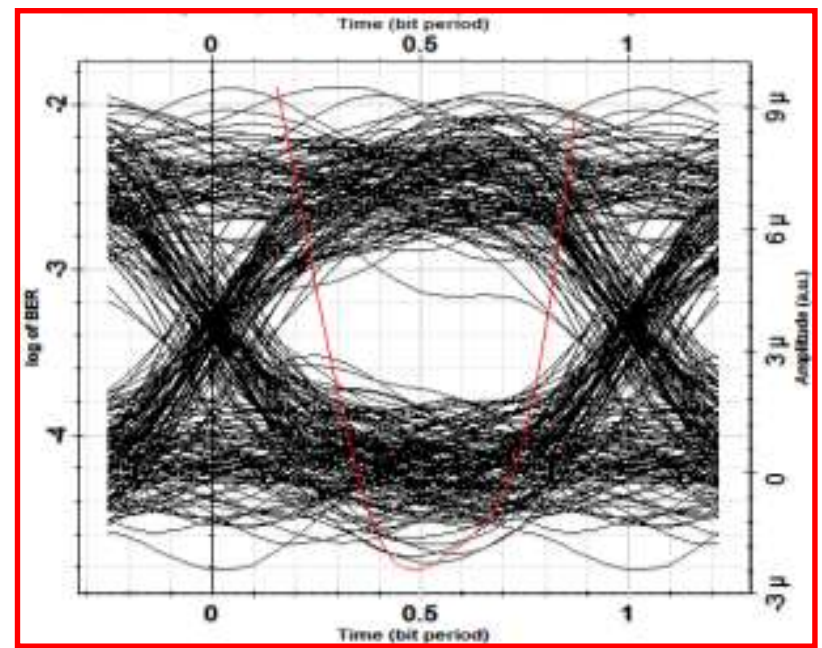

Fig.12. Eye diagram for GPON at distance $50 \mathrm{~km}$ using transmitted power of $3 \mathrm{dBm}$.

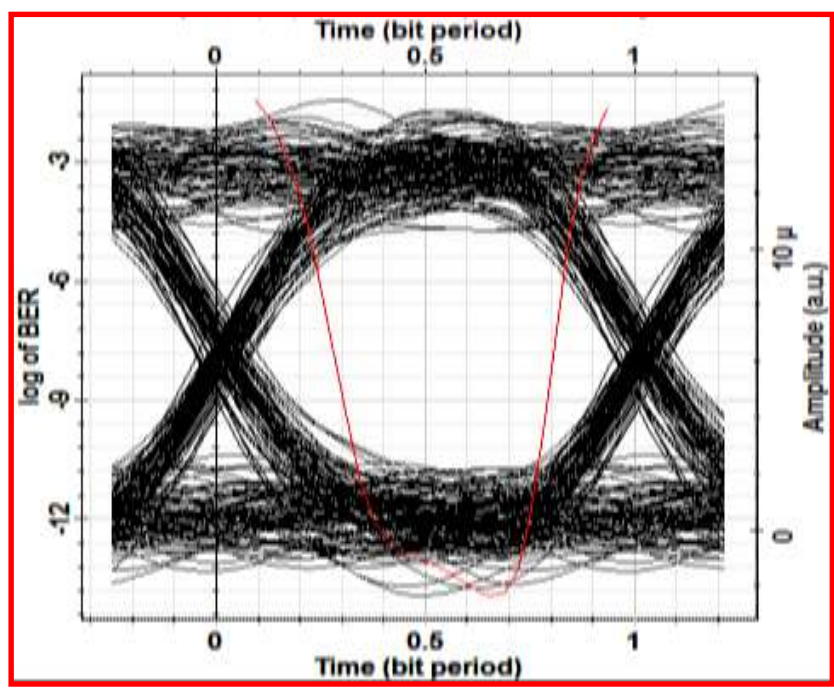

Fig.13. Eye diagram for AON PtP at distance $50 \mathrm{~km}$ using transmitted power of $-3 \mathrm{dBm}$

\section{REFERENCES}

[1] G. Keiser, Optical fiber communications, fourth ed., 2010.

[2] N. Ansari and J. Zhang, Media access control and resource allocation: For next generation passive optical networks: Springer Science \& Business Media, 2013.

[3] C. DeCusatis, "Handbook of fiber optic data communication: a practical guide to optical networking," Fourth ed London: Academic Press, 2013.

[4] M. M. Al-Quzwini, "Design and Implementation of a fiber to the home FTTH access network based on GPON," International Journal of Computer Applications, vol. 92, 2014.

[5] L. Koci, T. Horvath, P. Munster, M. Jurcik, and M. Filka, "Transmission convergence layer in XG-PON," in Telecommunications and Signal Processing (TSP), 2015 38th International Conference on, 2015, pp. 104-108. 
[6] S. M. F. S. F. Gillani, M. A. Khan, and M. K. Shahid, "Reach extendibility of passive optical network technologies," Optical Switching and Networking, vol. 18, pp. 211221, 2015.

[7] S. Bindhaiq, A. S. M. Supa, N. Zulkifli, A. B. Mohammad, R. Q. Shaddad, M. A. Elmagzoub, and A. Faisal, "Recent development on time and wavelength-division multiplexed passive optical network (TWDM-PON) for next-generation passive optical network stage 2 (NG-PON2)," Optical Switching and Networking, vol. 15, pp. 53-66, 2015.

[8] J. Wei, Q. Cheng, R. V. Penty, I. H. White, and D. G. Cunningham, "400 Gigabit Ethernet using advanced modulation formats: performance, complexity, and power dissipation," IEEE Communications Magazine, vol. 53, pp. 182-189, 2015.

[9] K. Wang, A. Gavler, C. M. Machuca, L. Wosinska, K. Brunnström, and J. Chen. (2016) Migration Strategies for FTTx Solutions Based on Active Optical Networks. IEEE Communications Magazine. 78-85.

[10] M. Radivojević and P. Matavulj, The Emerging WDM EPON: Springer, 2017.

[11] K. Wang, C. M. Machuca, L. Wosinska, P. J. Urban, A. Gavler, K. Brunnström, and J. Chen, "Techno-Economic Analysis of Active Optical Network Migration Toward Next-Generation Optical Access," Journal of Optical Communications and Networking vol. 9, pp. 327-341, 2017.

[12] M. Pradeep, B. Pavithra, R. Pooja, S. Parameswari, and M. Pandi, "A Survey of FTTH Elements Based on Broadband Access Network," Asian Journal of Applied Science and Technology (AJAST), vol. 1, pp. 54-59, 2017.

[13] H. S. Abbas and M. A. Gregory, "The next generation of passive optical networks: A review " Journal of Network and Computer Applications, vol. 67, pp. 53-74, 2016.

[14] K.-M. Chen, Y.-L. Yu, S.-K. Liaw, Z.-K. Lee, Y.-W. Lee, and N. Goto, "BER and Q factor evaluation of narrow-linewidth fiber ring laser," in Photonics (ICP), 2016 IEEE 6th International Conference on, 2016, pp. 1-3. 